\title{
ПРОБЛЕМЫ ИНТЕГРАЦИИ ПРЕПОДАВАНИЯ КУРСА ОБЩЕЙ ХИМИИ ПРИ ПОДГОТОВКЕ СТУДЕНТОВ ВЫСШЕЙ МЕДИЦИНСКОЙ ШКОЛЫ
}

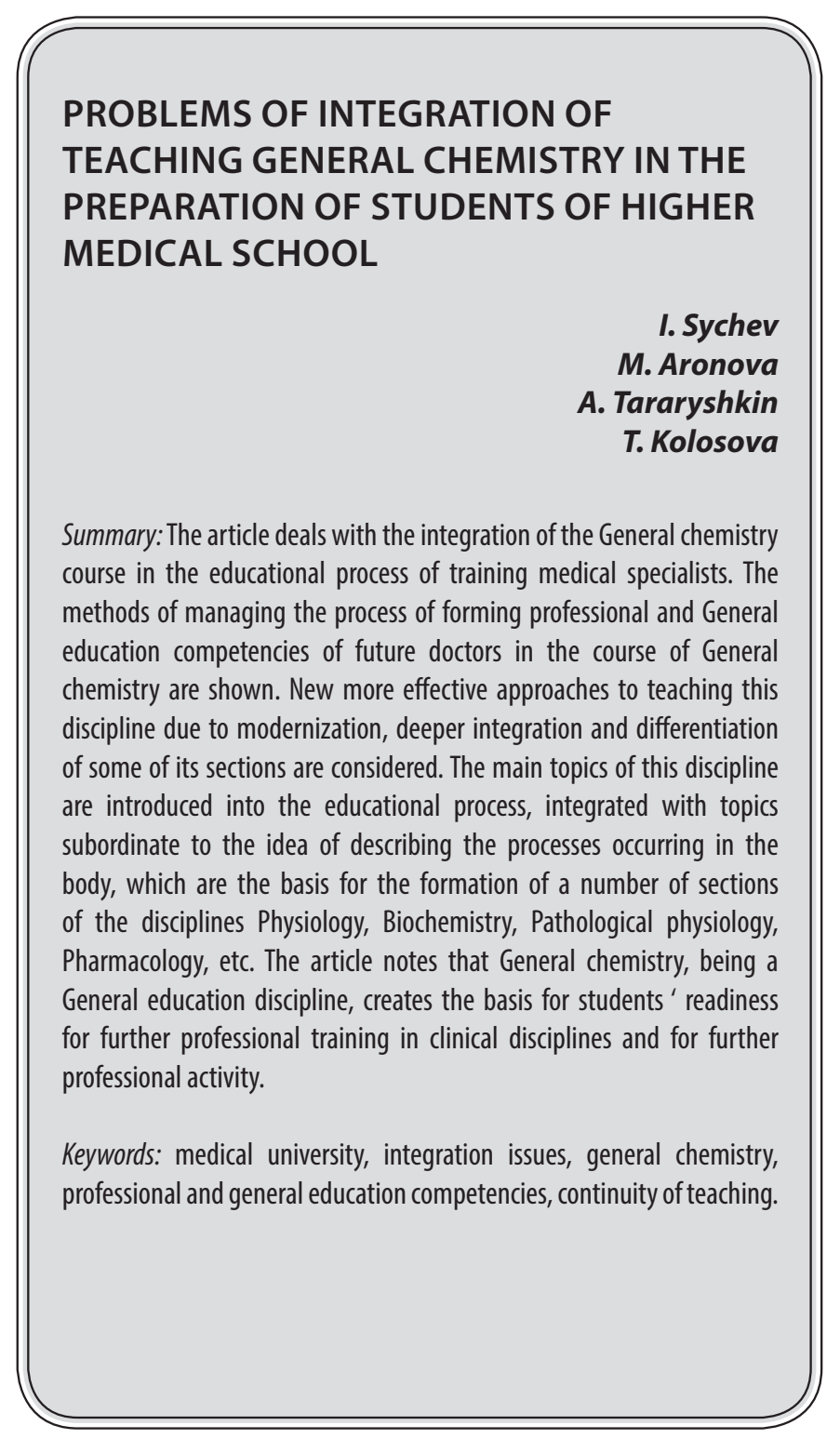

Summary: The article deals with the integration of the General chemistry course in the educational process of training medical specialists. The methods of managing the process of forming professional and Genera education competencies of future doctors in the course of Genera chemistry are shown. New more effective approaches to teaching this discipline due to modernization, deeper integration and differentiation of some of its sections are considered. The main topics of this disciplin body, which are the basis for the formation of a number of sections of the disciplines Physiology, Biochemistry, Pathological physiology, armacology, etc. The article notes that General chemistry, being for further professional training in clinical disciplines and for further

Keywords: medical university, integration issues, general chemistry, professional and general education competencies, continuity of teaching.

\section{Сычев Игорь Анатольевич}

Д.б.н., дочент, Рязанский государственный медицинский университет имени академика И.П. Павлова

i.sytchev@rzgmu.ru

Аронова Мария Александровна

К.п.н., старший преподаватель, Рязанский государственный медицинский университет имени академика И.П. Павлова mariia.aronova@mail.ru

Тарарышкин Александр Петрович К.м.н., дочент, Рязанский государственный медицинский университет им. академика И.П. Павлова alextarar2017@mail.ru

Колосова Татьяна Юльевна

К.х.н., дочент, Рязанский государственный медицинский университет имени академика И.П. Павлова tkkolosova@gmail.com

Аннотация: В статье рассмотрены вопросы интеграции курса Общая химия в учебно-воспитательном процессе подготовки специалистов медицинского профиля. Показаны способы управления процессом формирования профессиональных и общеобразовательных компетенций будущих врачей в рамках изучения курса Общая химия. Рассмотрены новые более эффективные подходы к преподаванию этой дисциплины за счет модернизации, более глубокой интеграции и дифференциации некоторых ее разделов. В учебный процесс внедрены основные темы данной дисциплины, интегрированные с темами, подчинёнными идее описания процессов, происходящих в организме, являющиеся основой для формирования ряда разделов дисциплин Физиология, Биохимия, Патологическая физиология, Фармакология и т.д. В статье отмечается, что Общая химия, являясь общеобразовательной дисциплиной, создает основу готовности студентов к последующему профессиональному обучению клиническим дисциплинам и к дальнейшей профессиональной деятельности.

Ключевые слова: медицинский вуз, вопросы интеграции, общая химия, профессиональная и общеобразовательная компетенции, преемственность преподавания.

постоянному профессиональному росту [1].

Образование будущего врача должно опираться, прежде всего, на фундаментальную теоретическую и практическую подготовку, а также на прочную мотивационную установку, на развитие интеллектуальных и личностных качеств студентов. Значимой составляющей теоретической базы подготовки студентов является дисциплина Общая химия [2]. Современный врач должен знать, какие процессы и по каким механизмам происходят в организме, уметь управлять этими процессами 
и на этом основании выбирать правильную стратегию и тактику лечения пациента.

Изучение дисциплины Общая химия происходит на первом курсе обучения, что имеет важное значение не только для формирования теоретических знаний и практических умений и навыков, но и для адаптации вчерашних школьников к требованиям и режиму высшей школы, способствует возникновению у первокурсников чувства личной ответственности, успешности и гордости за возможность обучения в медицинском Вузе.

В этой связи интегрированный подход к обучению студентов-первокурсников имеет важное значение. Дисциплина Общая химия легко интегрируется не только с такими теоретическими дисциплинами, как Биология, Физика, но и с некоторыми аспектами таких специальных дисциплин, как Физиология, Биологическая химия, Анатомия, Гистология. Курс Общей химии обеспечивает формирование базовых химических, химико-биологических, медицинских компетенций и создает основу готовности студентов к последующему профессиональному обучению клиническим дисциплинам [3] и к дальнейшей профессиональной деятельности.

Общая химия принадлежит к числу фундаментальных общетеоретических дисциплин. Многие разделы данного курса возникли на стыке Физической химии, Биохимии, Фармацевтической химии и Биоорганической химии. В состав современной дисциплины Общая химия входят следующие наиболее важные для подготовки студентов разделы: основы химической термодинамики и термохимии; химическая кинетика; химия комплексных соединений; химия растворов электролитов; химия растворов неэлектролитов; химия дисперсных систем; некоторые разделы неорганической химии и аналитической химии. В структуре дисциплины Общая химия все эти разделы интегрированы друг с другом, подчинены идее описания процессов, происходящих в организме, и являются основой для формирования некоторых тем дисциплин Физиология, Биохимия, Патологическая физиология, Фармакология.

Курс Общая химия выполняет в высшей медицинской школе такие основные функции, как:

- вооружает студентов основами знаний для изучения других химических, общетеоретических и специальных дисциплин, необходимых для понимания процессов, происходящих в организме человека в норме и при различных видах патологии;

- формирует у студентов практические навыки работы с приборами, оборудованием, химической посудой и реактивами;

- развивает способность к «самостоятельному умению мыслить с позиции науки, выходить за рам- ки узкой специальности в решении комплексных проблем» [4] ;

- способствует формированию у студентов интереса к участию в научных исследованиях;

- обеспечивает преемственность довузовского и вузовского химического образования;

- помогает студентам первых курсов адаптироваться в Вузе $[4,5]$.

Будущие медики получают теоретические знания по указанным выше разделам этой дисциплины на лекциях, практических работах, в процессе решения упражнений и задач и, особенно, ситуационных задач медицинской направленности.

Практические умения и навыки студенты приобретают в процессе выполнения лабораторных работ, где они учатся обращаться с химическим оборудованием и посудой, брать навески веществ, готовить стандартные и рабочие растворы, проводить реакции в различных условиях, работать с газовыми горелками и водяными банями. Выполняя определенную стандартизированную последовательность действий, описанную в лабораторном практикуме, студенты получают первые практические навыки работы с приборами: определение $\mathrm{pH}$

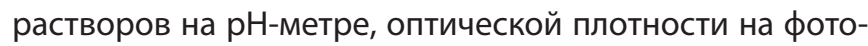
электроколориметре, использование весов аптечных и электронных для взятия точных навесок веществ, водяной бани для нагревания растворов, лабораторной центрифуги для выделения осадков.

В лабораторном практикуме студенты знакомятся с различными методами титрования для количественного определения веществ в растворах. Полученные умения и навыки будут совершенствоваться в процессе изучения дисциплины Биологическая химия, и использоваться в научно-исследовательской и лабораторной работе врачей-лаборантов. Анализ биологических жидкостей (крови, плазмы, сыворотки, мочи, слюны и т.д.) химическими и физико-химическими методами во многих случаях необходим для понимания протекания процессов В живом организме при постановке диагноза.

Анализ уровня химической подготовки студентов медицинских вузов с учетом тенденций развития высшей школы и новых требований к профессиональным и общеобразовательным компетенциям специалистов позволил нам выявить недостатки в современном преподавании дисциплины Общая химия в высшей медицинской школе. Несмотря на всю значимость этой дисциплины для подготовки студентов, количество часов лекционных и практических занятий выделенных на ее освоение явно недостаточное. Оно составляет около $10 \%$ учебного времени первокурсника или 1,1\% от всего времени обучения в Вузе. Учебно-методическое 
обеспечение курса Общая химия устарело, что создает сложности в процессе преподавания и снижает уровень мотивации студентов при обучении.

Необходимы новые более эффективные подходы к преподаванию дисциплины за счет модернизации, более глубокой интеграции и дифференциации некоторых ее разделов и собственно процесса обучения для формирования профессиональных и общеобразовательных компетенций студентов-медиков.

Одним из таких подходов является интегративный подход к обучению студентов-первокурсников. Значимость этого подхода обусловлена преемственностью в преподавании дисциплины Общая химия и дисциплин, изучаемых студентами на младших курсах: Биоорганическая химия, Физика, Биология, Биологическая химия, Нормальная физиология, Патологическая физиология, Фармакология, Патологическая анатомия, Гистология.

В рамках реализации данного подхода к оптимизации учебного процесса преподавателями кафедры Общей химии Рязанского Государственного медицинского университета были:

- разработаны и утверждены рабочие программы и календарные планы;

- отобраны наиболее значимые теоретические разделы и темы дисциплины;

- подготовлены и апробированы расширенные лабораторные практикумы с теоретическим обоснованием каждой темы изучаемой дисциплины;

- создан комплекс наглядных пособий, отвечающих современным требованиям фундаментального медицинского образования;

- подготовлен и внедрен блок ситуационных задач и упражнений с медико-биологической направленностью, элементами интеграции, изучением сущности химических процессов, протекающих в биосистемах.

С целью формирования профессионального интереса будущих врачей преподаватели кафедры привлекают студентов к участию в научно-исследовательских теоретических и практических работах, олимпиадах, конференциях и к работе студенческого научного общества.

Рассмотрев программы ряда дисциплин, преподаваемых будущим врачам, мы выделили в курсе Общая химия блоки знаний полифункционального характера, необходимые для изучения всех последующих теоретических и клинических дисциплин: строение веществ и их биологическая функция в организме человека; комплексные соединения, хелатные комплексы, по- нятие о металлолигандном гомеостазе и причинах его нарушения, биокомплексы; роль воды и растворов в жизнедеятельности организма, способы выражения концентрации вещества в растворе, коллигативные свойства растворов, диффузия и осмос; водородный показатель и его значение для клеток и тканей организма; сильные и слабые электролиты в организме; буферные растворы, буферное действие, как основной механизм протолитического гомеостаза; гетерогенные реакции и равновесия; окислительно-восстановительные реакции и равновесия; основы количественного анализа; основы термохимии и термодинамики.

Важным и профессионально-направленным в структуре курса Общая химия для медицинских вузов является модуль «Учение о растворах. Протолитические и гетерогенные равновесия». Системообразующим понятием этого блока является общефундаментальное понятие раствора [6]. Свойства растворов и явлений, происходящие в них, объясняют теория электролитической диссоциации, законы Рауля, Вант-Гоффа, Сеченова.

Другим важным блоком в химической подготовке врача является тема «Буферные растворы», при изучении которой, студенты знакомятся с видами буферных растворов плазмы крови и механизмами их действия. Этот блок знаний в дальнейшем развивается и дополняется при изучении дисциплин Нормальная физиология, Патологическая физиология, Биохимия и некоторых клинических дисциплин (Терапия, Анестезиология, Хирургия и т.д.).

Лабораторный практикум по дисциплине Общая химия является базой для подготовки студентов к изучению дисциплин Клиническая лабораторная диагностика, Медицинская микробиология, Фармакология, и для освоения методов санитарно-гигиенических лабораторных исследований. В ходе выполнения лабораторных работ студенты приобретают навыки работы с аналитическими приборами, растворами, химической посудой и реактивами.

Таким образом, преподаваемый нами курс Общая химия в рамках интеграции отличается от ранее преподаваемых курсов более определенной медико-профессиональной направленностью. Эта профессиональная ориентация выражается в тщательном отборе учебного материала, необходимого для теоретической и практической подготовки, как врача широкого профиля, так и узких специалистов - стоматологов, педиатров, санитарных врачей, а также интеграцией этого материала с содержанием обучения на теоретических и клинических кафедрах нашего вуза. 


\section{ЛИТЕРАТУРА}

1. ФГОС В0 по специальности 31.05 .02 Педиатрия (уровень специалитета), пр. № 853 от 17.08.2015 г. (электронный ресурс). - URL:http://минобнауки.pф/ документы/6412.

2. Литвинова Т.Н., Выскубова Н.К., Овчинникова С.А., Кириллова Е.Г., Слинькова Т.А. Межпредметная интеграция курса общей химии в медицинском вузе // Фундаментальные исследования. - 2004. - № 3. - С.73-74. (дата обращения: 16.02.2020).

3. Литвинова Т.Н, Формирование химической компетенции студентов медицинского вуза // Современные педагогические технологии в преподавании предметов естественно-математического цикла: сборник научных трудов. - Ульяновск: УЛГПУ им. И.Н. Ульянова, 2017. - С.44-47.

4. Бабаев Д., Минасов Н. Интеграция курса общей химии при подготовке будущих врачей // Актуальные проблемы современности: наука и общество 2018. - №3. - . $.53-57$.

5. олосова Т.Ю., Кубасова Л.В. Практикоориентированные технологии в высшем образовании как фактор адаптации студентов первого курса (на примере преподавания биоорганической химии в медицинском вузе) // Личность в меняющемся мире: здоровье, адаптация, развитие: сетевой журн. 2019. Т.7, № 4 (27). Доступно по ссылке: http://humjournal.rzgmu.ru/art\&id=403

6. Литвинова М.Г., Литвинова Т.Н. Современный курс химии в медицинском вузе: цели, содержание, структура // Современные проблемы науки и образования. - 2018. - №4.

○ Сычев Игорь Анатольевич (i.sytchev@rzgmu.ru), Аронова Мария Александровна (mariia.aronova@mail.ru), Тарарышкин Александр Петрович (alextarar2017@mail.ru), Колосова Татьяна Юльевна (tkkolosova@gmail.com).

Журнал «Современная наука: актуальные проблемы теории и практики»

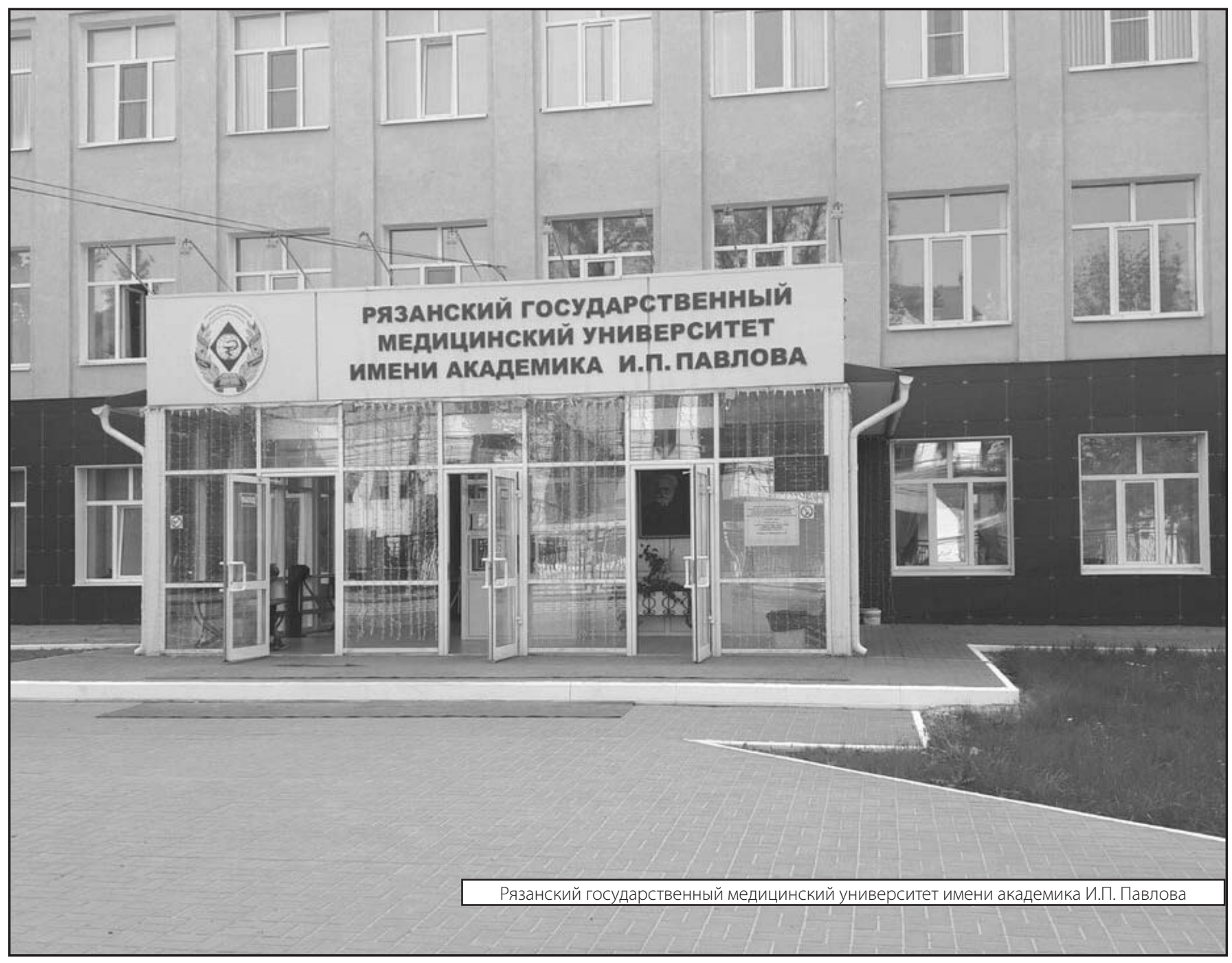

